\title{
O "veneno" e a adrenalina na "vida do crime": corpo, emoções e subjetivação
}

\author{
Danielli Vieira ${ }^{1}$ \\ Instituto Federal de Santa Catarina
}

Resumo: O artigo apresenta dois conjuntos de sensações, emoções que perpassam a experiência na "vida do crime" a partir de duas pesquisas de campo centradas em narrativas de adolescentes que cumpriam medidas socioeducativas. Trata-se de uma aproximação a uma experiência em que se vive, ao mesmo tempo, "no veneno" com sensações que misturam angústia, sofrimento, raiva e tristeza - e na intensidade de uma "vida loka" marcada por adrenalina, presenteísmo, "alterações". Discute-se, ainda, a função terapêutica da narrativa como forma de desabafo, bem como a elaboração do "veneno", dos castigos e torturas sofridos, em termos de "fortalecimento".

Palavras-chave: emoções; adolescentes "em conflito com a lei”; narrativas. 


\title{
The "poison" and the adrenaline in the "life of crime": body, emotions and subjectivation
}

\begin{abstract}
The article presents two sets of sensations, emotions that permeate the experience of "life in crime", that has its starting point at two field researches centered on narratives of adolescents submitted to socio-educational measures. It is about an experience that brings together two aspects at the same time, such as a feeling of living "in the poison" ("no veneno") - with sensations that mix anguish, suffering, anger and sadness - and the intensity of living a "thug life" ("vida loka") marked by adrenaline, presentism. The article also discusses the therapeutic function of the narrative as a way of venting, as well as the elaboration of the "poison", of the punishments and tortures suffered, in terms of "strengthening".
\end{abstract}

Keywords: Emotions, adolescents “in conflict with the law", violence, narratives.

\section{El "veneno" y la adrenalina en la "vida del crimen": cuerpo, emociones y subjetivación}

\begin{abstract}
Resumen: El artículo presenta dos conjuntos de sensaciones, emociones que impregnan la experiencia en la "vida del crimen" basada en dos investigaciones de campo centradas en las narrativas de adolescentes que cumplieron con medidas socioeducativas. Es una aproximación a una experiencia en la que uno vive, al mismo tiempo, "en veneno", con sensaciones que mezclan angustia, sufrimiento, ira y tristeza, y en la intensidad de una "vida loka" marcada por la adrenalina, el presentismo. También discute la función terapéutica de la narrativa como una forma de explosión, así como la elaboración del "veneno", los castigos y las torturas sufridas, en términos de "fortalecimiento".
\end{abstract}

Palabras clave: emociones; adolescentes "en conflicto con la ley"; narrativas. 


\author{
Aí, X, fica calmo \\ Não apavore \\ O veneno vai passar, a qualquer hora \\ Tem um ditado que diz: \\ "Coração de vagabundo bate na sola do pé" \\ Mas o problema é que ele bate, né? \\ Quando eu era pequeno, meu pai me batia \\ Olhava em meus olhos e ainda ria \\ Mamãe me dizia: Joe, deixa quieto \\ Mas agora eu cresci, pode crer, o papo é reto \\ Entrei no sistema, mas eu corro pelo certo \\ Sentado aqui, eu não tenho um amigo \\ Só meus irmãos, que falam que fecham comigo \\ Sou Joe MC, superior... \\ Tenho orgulho, bato no peito \\ Pois quem não deve não treme \\ Não tenho medo de ninguém \\ Se fode, não tenho dó \\ Ando sozinho, não, não, com os irmão do lado \\ $(\mathrm{Joe})^{2}$
}

$\mathrm{A}$ s discussões apresentadas no que segue tratam de emoções e sensações que permeiam a experiência de adolescentes no que eles circunscreveram como "vida no crime". Elas foram desenvolvidas a partir de duas etnografias (VIEIRA, 2009; 2012; 2014) centradas em narrativas de meninas e meninos em cumprimento de medidas socioeducativas.

A primeira pesquisa de campo (VIEIRA, 2009) - para uma dissertação - foi realizada em instituições de internação para meninos - locais em que viviam longos períodos de isolamento e privados de liberdade. Nesse contexto de interlocução, o que mais chamou a atenção sobre a experiência de internação narrada pelos jovens foi a questão de uma acentuação da dimensão de "estar no veneno" e da narração como possibilidade de "desabafar", de colocar para fora o que eles chamavam de "veneno". Tal categoria apareceu quando descreviam sua condição atual (estar "preso") e também nas referências aos aspectos de sofrimento, de dificuldades na vida que levavam "no crime". Essa ênfase trouxe à tona uma importante dimensão da vida desses jovens que, em geral, é pouco visibilizada. Quando pensamos em jovens "envolvidos" com o tráfico, o que vem mais facilmente à mente é o "ethos guerreiro" (ZALUAR, 1995), a virilidade, a coragem, as guerras. Aprendi que os "guerreiros" também sofrem: ao verem situações difíceis na família, ao presenciarem a morte de um amigo assassinado, ao se lembrarem de pessoas que mataram ou que ajudaram a matar, com o trabalho nas madrugadas, por estarem privados da liberdade. Em suma, foi mais um momento na trajetória de pesquisa que mostrou a importância de uma abertura às múltiplas possibilidades de configuração dos sujeitos e de suas experiências.

Já a pesquisa de campo para a tese (VIEIRA, 2014) deu-se em locais nos quais eram aplicadas medidas socioeducativas de semiliberdade e de liberdade assistida para meninas e meninos. Nesse contexto, em que estavam sob menos vigilância e não submetidos a castigos corporais, vieram à tona relatos sobre situações em que sofreram castigos, torturas, humilhações dentro das instituições de 
internação e na rua. Tais histórias são aqui analisadas no quadro da dimensão de "viver no veneno". Além disso, outro conjunto de emoções - por eles tratadas em geral em termos de adrenalina - permeou as narrativas e se refere a uma dimensão bem diferente: de aventura, de diversão, de experimentação.

No presente artigo, assim trata-se de pensar o lugar das emoções e de uma série de elementos presentes na experiência de institucionalização (castigos, humilhações, "ortopedias morais", medicalização) que fazem parte da constituição de determinados corpos e sujeitos. Nesse sentido, é importante salientar que:

\begin{abstract}
As emoções não são substâncias, objetos descritíveis cujos equivalentes seriam facilmente identificáveis em duas culturas diferentes por meio do simples exame léxico. Elas são atitudes provisórias que manifestam a tonalidade afetiva do indivíduo na sua relação com o mundo. A causa das emoções, seus efeitos sobre o indivíduo ou sua modalidade de expressão não se concebem fora do sistema de significados e de valores que regem as interações no grupo. (LE BRETON, 2009: 152)
\end{abstract}

O "veneno"

O termo "veneno" foi recorrente nas narrativas dos interlocutores. Ele apareceu quando descreviam sua condição atual (estar "preso"3) e também nas referências à vida que levavam "no crime": "Só veneno esse lugar, né" (Wesley); "Ééé, o mundão assim do crime também não vale a pena não, só ilusão mesmo, né... o cara tá bem, depois tá aí, daí é só veneno, né. Daí tem que refletir bem pra a hora que sair não fazer mais isso, né, fazer só coisinha certa, né, pra não se incomodar, né" (Wesley); "Tinha muito veneno na cabeça" (Joe).

Wesley falou do sofrimento que sentiu ao ver um amigo ser assassinado em termos de "veneno": "oh, daí mesmo, só veneno, né. Matar assim um parceiro assim do cara, o cara fica até ruim, né, meu deus, né". Durante uma conversa coletiva, um dos jovens englobou toda a vida no mundo terrestre como uma vida de veneno, de inferno: "esse mundo aqui não é nada, só veneno, aqui é um inferno mesmo... lá pra frente é que nós vamo ver o outro lado". Carlos falou sobre formas de descontar o "veneno": "Na hora só veneno, pegar e sentar o laço mesmo, [...] é muito veneno mesmo, só desabafa no gatilho do revólver, vai que vai. [...] aí eu ficava mais às pampa, descontava o veneno".

Em conversa com Joe, perguntei diretamente o que significava "veneno" e ele respondeu que é "tudo que é ruim", que é acumulado dentro da pessoa e pode fazê-la sofrer. Joe afirmou, ainda, que "o veneno fortalece". De acordo com ele, os sofrimentos e o fato de ter que lidar com situações diversas de violências tornam a pessoa mais forte. Dessa forma, violências sofridas podem ser a causa de acúmulo de "veneno", de "sofrimento" e, ao mesmo tempo, podem ser efeito do "veneno", quando utilizadas para expurgá-lo. Sobre essa dupla percepção a respeito das violências (como causa e como efeito), algumas reflexões de Nietzsche sobre a moral dão-nos pistas interessantes. Em sua Genealogia da Moral (1998: 12) aponta que, para que se faça uma crítica dos valores morais, é preciso conhecer as condições nas quais eles nasceram e sob as quais se desenvolveram e se modificaram: "(moral como consequência, como sintoma, máscara, tartufice, doença, mal-entendido; mas também moral como causa, medicamento, estimulante, inibição, veneno)" (destaques nossos). Theophilos Rifiotis, em orientação, lembrou-me que pharmakos em grego significa tanto remédio, quanto veneno e

3 Os Centros de internação para cumprimento de medidas socioeducativas do estado de Santa Catarina apresentavam, à época (primeira década dos anos 2000), estrutura, forma de organização e corpo de funcionários similares ao tradicional modelo prisional. Isso explica o acionamento por parte dos jovens das expressões "cadeia", bem como "estar preso", quando se referiam a essas instituições. 
que, entre os makonde (tribo moçambicana na qual fez campo), a categoria "ntela" é que traz esse duplo sentido. No sistema xamânico Siona, analisado por Esther Jean Langdon (1988), o conceito de dau é elemento essencial tanto na cura quanto na causa das doenças. Além disso, consiste na fonte de poder do xamã. Assim como o veneno, o dau pode causar sofrimento, infortúnio, mas, por ser fonte de "poder", de "fortalecimento", pode viabilizar a cura através da mediação do xamã.

Por fim, Joe disse também que o "veneno" relacionado aos sofrimentos que alguém passa pode ser "descontado" por meio de brigas ou "coisas mais graves". Nesses casos, a experiência de sofrimento relaciona-se também a sentimentos como amargura, raiva e ódio, que podem ser descontados por meio da utilização de violências. Trata-se das situações descritas por Carlos: "desabafa no gatilho do revólver" e "estocar para desabafar". Nessas circunstâncias, as violências atuam como meios de expurgar a raiva, o sofrimento. É preciso entender que esse tipo de modalidade de expurgo do sofrimento, de manifestação da raiva, mostrava-se a esses sujeitos como o caminho conhecido, como o caminho mais próximo. No que toca à dimensão das políticas, como argumenta Rifiotis (2006), sem repensar as matrizes de sociabilidade nos modelos presentes, não é possível retirar as consequências teóricas que nos permitam superar os limites atualmente colocados, bem como discutir novas direções de intervenção social. Por outro lado, na interlocução com Carlos sobressaiu uma dimensão politicamente muito importante em relação ao processo de narrar e de escutar. O menino, que "aprendeu" com 13 anos a matar e que só encontrava como caminho de descarrego o "gatilho do revólver" ou "estocar", "furar" companheiros de cela, diz, no final da nossa conversa, que está se sentindo "às pampa"4 e que "leva mais desabafar do que estocar alguém”.

\title{
"Narrar para desabafar"
}

\author{
Cercado por paredes e detrás de uma cela. \\ Saudades da família e também da minha favela. \\ CIP ou cadeia, coração amargurado. \\ À noite a mente pesa, com lembranças do passado \\ (Ângelo, trecho de letra de rap)
}

As narrativas constituem um meio de falar sobre eventos anteriores em que necessariamente aparecerá a dimensão moral (percepções, valorações), bem como um ponto de vista ou um "sujeito em mudança", que se constrói na narrativização. De acordo com Renato Rosaldo (1993), que tece seus comentários com base na concepção de Ricoeur, as narrativas modulam as experiências temporais e estas, por sua vez, dão corpo às narrativas. Dessa forma, há um agenciamento retrospectivo da experiência, há uma seleção e uma interpretação pautadas por um ponto de vista localizado no presente. É nesse sentido que as narrativas não são tanto representações da experiência, mas são constitutivas dela, modulam-na (BRUNER,1986; ROSALDO, 1993). A “narrativização”, assim, ao implicar um processo de seleção, de interpretação e de reelaboração com base no presente, configura um espaço para a produção de experiências, eventos, sujeitos. É a partir dessas considerações que se pode falar em termos de um sujeito (ou de posições de sujeito) que emerge(m) ao narrar, que se constitui(em) nesse processo. 
Em nossas pesquisas (VIEIRA, 2009; 2014) encontrou-se uma pluralidade de figuras e posições de sujeito que atravessavam os jovens, mas no que tange aos objetivos do presente artigo, as reflexões concentram-se em uma dimensão possível do processo de narrar. No contexto de institucionalização, especialmente, no regime de internação, chamou a atenção a questão de uma acentuação da dimensão de "estar no veneno" e da narração como possibilidade de "desabafar", de colocar para fora o que eles chamavam de "veneno". O tom de desabafo prevaleceu nas conversas com os jovens internados. Quando há "desabafo", há experiências de dificuldades, de sofrimentos. Eles desejavam pôr para fora o "veneno".

Antes de iniciar a pesquisa de mestrado, algumas pessoas desencorajaramme, argumentando que seria difícil os jovens falarem comigo sobre a temática de homicídios. Entretanto, muitos dos meninos contatados quiseram falar. Além disso, a maioria contou histórias na primeira pessoa, vivências próprias. Mesmo aqueles que contaram histórias das quais não tinham participado não deixaram de falar sobre suas próprias vidas, sobre suas trajetórias pessoais. Bob me disse que eu era a primeira pessoa a saber daquelas coisas e Carlos falou: "isso aí é uma coisa que é só minha e dos irmãos, dos irmão da cadeia e a dona agora.”. Pitu confidenciou que não gostava muito de falar sobre essas coisas, mas que iria falar para: "colaborar com a senhora". Ressalto que expliquei com clareza os objetivos do meu trabalho e que eu estava ali para ouvir apenas aqueles que quisessem falar.

Pensei em muitos fatores que poderiam dar conta da disponibilidade para contar histórias sobre o tema, para contar suas próprias histórias. Levei em consideração o fato de os jovens saberem que eu manteria o sigilo das identidades e que poderiam dar as suas versões das histórias, sem que isso os prejudicasse. Eu provavelmente nunca mais os veria e não faria um relatório acerca deles dirigido ao juiz, como no caso das pedagogas e psicólogas que trabalham nas instituições. A questão de eu também ser jovem e de ser mulher (eles mantêm contato apenas com os funcionários da instituição e com parentes - geralmente, as mães) também tem que ser levada em conta, assim como a vontade de contar sua história, de se sentir ouvido sem julgamentos. Mas, o que considero mais relevante, pois foi algo apontado explicitamente por alguns deles, foi a oportunidade de desabafar.

É importante salientar que o tom de desabafo deve ser entendido como decorrente da forma com que se deu a nossa relação. Eu não representava para eles nem uma pessoa igual (de dentro), nem uma pessoa alheia, que não mereceria confiança. Além disso, coloquei-me desde o início numa posição de escuta. Eles sabiam que era uma escuta diversa daquela das pessoas da instituição, já que era uma escuta sem pretensão de ensinamento, de avaliação, e, além disso, que manteria o sigilo em relação às suas identidades. A seguir, descrevo uma interlocução na qual a questão do "narrar para desabafar" se mostrou claramente.

Em uma de minhas visitas a campo, Carlos foi o primeiro menino que se disponibilizou a falar. Ele tinha uma postura de igualdade em relação a mim, falava olhando em minha direção e, em geral, com tranquilidade. Contou-me a sua vida: seu envolvimento com o tráfico e com o crime organizado; suas mudanças de cidade; suas fugas e sua estada, mesmo sendo menor, em uma delegacia junto aos maiores; os assassinatos que cometeu; sua relação com a família, com sua filha; os pensamentos sobre a possibilidade de "mudar de vida". Conversamos durante duas horas. Algo que vale pontuar é que tal menino passou por uma espécie de "aprendizado", cujo objetivo era o de não nutrir sentimento algum, além da raiva, para ser capaz de matar sem constrangimentos. Carlos contou também que usava 
muita cocaína e que, sob seu efeito, fazia coisas que não imagina como conseguiu fazer. Quase no final da nossa conversa, relatou que, estando internado, o pensamento ficava "a milhão". Às vezes acordava a noite assustado, pois era "só veneno nesse lugar”. Falou então sobre a vontade de fugir e contou-me que já havia visto internos que se suicidaram dentro da "cadeia" por "ficar depressivo e se matar". Nesse ponto, contou então que achava que não tinha pensado em se matar durante outras internações, pois "descontava minha depressão em cima dos outros", "estocava" (furava) espeto em outros, "aí eu ficava mais às pampa, descontava o veneno". Depois de mais alguns minutos conversando, eu disse para ele que já estávamos falando há uma hora e meia, ele então disse o que segue:

\begin{abstract}
Orra! Tudo isso dona?! Ô, tempo pra caralho, trocando uma ideia, né. Eu já (...), o cara vai desabafando, vai falando, vai ficando bem mais às pampa assim. $\hat{O}$, o cara fica só na cadeia, pá, vai trocar ideia com as dona alí ${ }^{5}$ cara fica no veneno, só sai no veneno, mesmo... ô já vem pra dentro do nível mesmo magoadão. $O$ cara troca uma ideia vai desabafando, pá, aí vai clareando a mente do cara, o cara vai pensando mais... o cara vai tendo uma visita o cara vai ficando mais às pampa.

Às vezes, em vez de furar...

É... desabafar leva mais do que chegar e furar alguém, pá, fazer uma coisa errada, né. Leva mais, conversar, desabafar... Leva mais desabafar do que estocar alguém. Desabafar o cara fica mais às pampa.
\end{abstract}

Outros meninos explicitaram que foi bom falar comigo para desabafar. José estava, no começo da nossa conversa, muito tenso, muito inquieto. Ele perguntou quanto tempo o gravador poderia gravar e eu disse que várias horas. E então, confidenciou que iria falar o máximo possível para não ter que voltar para a "cela". Ele estava, provavelmente, transtornado pelo tempo em que esteve trancado. No decorrer da interlocução, foi se soltando e mostrou-se um dos entrevistados mais performáticos. Nas instituições que tive a oportunidade de conhecer, mesmo com os esforços para manter um caráter de medida socioeducativa, uma das grandes limitações era a falta de atividades desse âmbito no cotidiano dos meninos. Em um período do dia eles estudavam, havia espaços para atividades físicas, mas contaram que passavam grande parte do dia nas celas e aproximadamente 12 horas durante a noite. Na dinâmica das instituições, a penalidade (denominada "medida disciplinar") para o descumprimento das regras impostas é o trancamento do jovem em sua "cela", às vezes por semanas, com saída apenas para banho e banho de sol. Não se está aqui tentando reproduzir os discursos que enfatizam o valor da ocupação em detrimento da reflexão, do tempo ocioso. $\mathrm{O}$ dilema é que o "tempo de parada" e a possibilidade de reflexão quando nas condições descritas, podem ter efeitos psicológicos, físicos e mesmo sociais muito sérios na vida desses sujeitos.

A percepção da narração como uma experiência de "desabafo", que gera sensações de tranquilidade, de bem-estar, de ficar "às pampa", remete à "função terapêutica" da narração. Elinor Ochs (2000) aponta que, em muitas comunidades, a atividade de resolver problemas via narração cooperativa é um símbolo de amizade ou pertencimento familiar. Em alguns casos, as histórias são levadas até especialistas da comunidade. De acordo com Ochs, em certas sociedades se diz que esses especialistas "desenrolam" os problemas; em outras, se fala em termos de "psicoterapia”.

As falas que trouxeram os meninos sobre o "desabafo" apontam no sentido de que, também na relação entre antropólogo que escuta e interlocutor que narra, 
pode ter lugar uma experiência restauradora, "terapêutica", no sentido de amenizar sofrimentos, angústias ("o veneno"). O "desabafo", no caso da presente pesquisa, foi situado de duas maneiras: como forma de expurgar o "veneno" relacionado à situação de estar preso (com pouquíssimas relações sociais, privação de liberdade, solidão) e de desabafar em relação a situações passadas que causam sentimentos de culpa, de "peso", de sofrimento.

É claro que no âmbito da Antropologia a função "terapêutica" da interlocução não é o objetivo, mas não deixa de ser um efeito. E, sendo assim, é preciso pensar sobre esse efeito e suas implicações para a pesquisa. No caso em questão, o "desabafo" foi uma das maneiras de apropriação da pesquisa por parte dos sujeitos. Essa forma de apropriação está ligada ao contexto institucional no qual se realizou a pesquisa e os efeitos desse contexto no cotidiano desses jovens.

\section{Castigos, torturas e humilhações}

Na ocasião da pesquisa de campo durante o mestrado, os interlocutores frisaram a condição de sofrimento que prevalecia quando internados. Contudo, não relataram diretamente situações de torturas, castigos extremos sofridos no interior das instituições. Somente durante o campo para tese, na Casa de Semiliberdade, é que despontou uma série de relatos sobre torturas, violações, castigos vivenciados no interior das instituições de internação e na rua. Aqui é importante lembrar que na primeira pesquisa, realizada no interior das instituições de internação, foram raros os momentos em que pude conversar com os adolescentes longe dos chamados monitores (com função similar a dos agentes prisionais). Tal vigilância bem como a desconfiança - como uma atitude de defesa e de prevenção por parte de internados - podem ajudar a entender por que esses relatos não apareceram naquela ocasião. Já na situação em que viviam em uma Casa de Semiliberdade, sentiram-se à vontade para compartilhar essas experiências. Primeiramente, foram relatos espontâneos que apareciam quando perguntados "como era na internação"; depois, dada a recorrência das descrições, passei a perguntar diretamente se haviam sofrido castigos, se tinham apanhado nas instituições.

Seguem relatos das meninas e meninos sobre humilhações, torturas, espancamentos, castigos que, de acordo com eles, ocorreram dentro de unidades de internação (provisória ou definitiva) para cumprimento de medida e na rua, levados a cabo por "monitores" e monitoras ou por agentes policiais. Trata-se de uma dimensão da experiência de estar "no crime", de ser "criminalizado", de ser institucionalizado, que foi trazida pelos sujeitos da pesquisa. São relatos que falam de uma presença estatal que deixa marcas visíveis no corpo e com efeitos mais difíceis de descrever no que toca aos aspectos da "alma" - psicológicos, psíquicos, subjetivos.

Passei veneno naquele lugar, foi horrível, acho que foi a pior parte da minha vida. Ficar presa. [...]. Algumas (monitoras), sabe, elas humilhavam a gente, sabe? Elas pisavam na gente (choro), elas faziam o que queriam com nós. Eu chamava alguém e pedia para me ajudar. O seu (gerente da instituição), coitado, tentava, não podia. $A$ gente fazia B.O contra elas, não adiantava, não adiantava. Elas ficavam ali debochando da nossa cara, achando que a gente era tola, sabe? [...]

Elas diziam que eu era louca, aqui (mostra as mãos) elas apertavam na mesa com a unha, sabe? E deixaram tudo marcado... ô, cara... Eu tava com as pernas todas rochas, sabe? Eu tenho marcas, assim, até hoje. Não sei se dá de ver. Tem uma aqui, ó (mostra marca na perna), até hoje.

Elas te deixavam com as pernas presas? 
É, uma vez eu fiquei das oito horas até as dez da noite. Elas diziam que era pra eu não me machucar. Mas não era pra eu não me machucar, era pra eu não chutar a porta e pro gerente não vir, sabe?

Essa menina, de acordo com seu relato, entrou depois num estado de depressão, machucava o próprio corpo e continuava a ser agredida pelas monitoras. Acerca das escarificações e cortes autoinfligidos, vale trazer as reflexões de Le Breton (2010: 221-241) sobre o infligir-se dor para lidar com um sofrimento indescritível; a dor como exorcismo de um trauma, como resistência; as escarificações como "cortes que cessam o sofrimento" 6 .

Contou, ainda que começaram a medicá-la de modo que ficava "praticamente anestesiada". Cabe ressaltar aqui a questão da medicalização como forma de controle e mesmo de punição, bem como a acusação de "loucura" para a legitimação daquele tipo de tratamento em relação à menina.

Seguem os relatos de meninos acerca de uma situação que parece ser corriqueira, de acordo com vários interlocutores. No momento em que são apreendidos por policiais, antes de serem levados às Delegacias, levam surras, choques, etc.

Os policial da BOPE, quando me pegaram, quase me mataram. Deram um monte de choque, quase me mataram. Tive que fingir que tava quase morrendo pra eles parar de bater.

Antes de chegar na DP... Eles levam pra algum lugar?

Me levaram lá no (...) desativado. Me levaram lá, quase me mataram.

$E$, quando chega na DP nesse estado, o delegado não pergunta nada?

Pergunta, mas nem adiantava nada. O delegado lá perguntou, né, se tinham me batido, pá. Daí o policial pegou assim no meu pescoço, que era pra falar que não tinha acontecido nada.

Mas não fica marca? Eles batem no corpo?

Aqui, ó, foi do dia que eles me pegaram (mostra cicatrizes). Esse machucado aqui foi do dia que a polícia me pegou. Cada vez que prendia, eles me batiam. Ou me catavam na rua. Quando eu tava foragido daí eu nunca, não tinha deixado eles me catar.

Mas quando eles pegam é feio? Até guri pequeno eles surram?

É feio. Ô, tinha um moleque - um irmão de um amigo meu -, o moleque tinha treze anos e quebraram a costela, tem um buraco aqui na barriga que quebraram as costelas dele. Treze anos de idade, tem um buraco aqui na barriga.

Uma vez, também, nós fizemos outro assalto. Aí nós corremos pra nossa casa [...] aí, nós dentro de casa... Cataram um outro amigo nosso, [...]. Daí o outro amigo nosso foi pra casa dele, e reconheceram ele pelo capacete. Daí foram e cataram ele dentro da casa dele. Daí ele foi e entregou tudo nós. Daí, nós dentro da casa, chegou umas duas viaturas da Tática e duas da Civil, mandaram todo mundo deitar no chão. Daí eles pediam arma, dinheiro. Daí nós falava que não tinha. Daí eles acharam as armas embaixo da casa. Daí eles vieram pedir o dinheiro. E nós não tinha, não tinha dinheiro a mais junto com nós, né? Nós falava que não tinha dinheiro e que não foi nós. Daí os policiais chegaram, me cataram e jogaram... Nós tinha bebida de álcool dentro da casa... Tacaram a bebida de álcool em mim e queimaram a minha perna aqui.

Tacaram fogo aí?

Não, com a maquininha de choque. Foi maquininha de choque.

Deve doer pra caramba...

Nossa, derreteu meu pé [...].

E, quando você tava machucado, você foi pra um hospital?

Não.

O machucado ficou...

Ficou em carne viva. Só a minha mãe que trazia as coisas pra mim sarar. Inflamou tudo lá dentro, que antes de eu vir aqui pra cá eu fiquei um tempão ali na (delegacia). Acho que uns 10 dias, por aí.

Já nos Centros de internação provisória e de internação:

${ }^{6}$ Numa outra obra na qual trata as especificidades das "condutas risco" na adolescência, o autor trabalha também a centralidade da pele nesse período da vida e os cortes como atos de passagem numa lógica do sacrifício (LE BRETON, 2007: 99-132). 
Paguei castigo, fiquei um mês de castigo.

Como é que era esse mês? Ficava trancado?

Trancado. Só dentro do quarto, só dentro do quarto, dentro da jega - um quartinho pequeninho. Um mês, sem pegar sol, sem nada.

Sim... Dormi uma semana, também, de algema e marca-passo, sem colchão.

Sem tomar banho, sem nada?

Sem nada.

Uma semana de algema... na perna também? No chão?

No chão.

E nessa semana o que você ficava pensando?

Eu ficava só sentado. E pensando nas coisas...

Há, também, os casos em que agentes policiais são chamados pela direção das instituições a entrar nessas últimas.

Aí eu botei na cabeça que eu ia mudar. Eu já botava na cabeça que ia mudar... mas cabeça fraca, né? Daí a polícia entrava, batia em nós: “Ah, não vou mudar, pá”. Não tem como mudar, porque vai crescendo uma revolta. Eu botei na cabeça que vou mudar e vou mudar, né?

Então foi um período ruim, né?

É, bem dizer, pra melhorar e tirar fora da sociedade, né? Mas daí a polícia entrava lá e batia em nós, daí...

Aí eles entravam no CIP lá e só eu apanhava. E a dona deixava eu apanhar. Ela ligava pra fazer revista, eles já entravam lá dando tiro, bala de borracha, na parede, não tem? Só pra assustar nós. A gente ficava pelado, botavam spray de pimenta no nosso rosto, nas nossas partes, não tem? Daí ali uma vez eu pensei em fugir, né? Daí eu vi, "Vou aguentar, né? Se eu fugir, vão me matar, a mesma coisa; eles querem me pegar". Eu pensei na minha mãe, aí fiquei. Fazer o quê?

Em uma conversa com um dos meninos, após ter contado que fiz uma palestra para os "socioeducadores" e técnicas de instituições de internação, ele me perguntou se eu tinha falado que seria melhor se eles não batessem mais nos internos. Contei o que discuti com os servidores naquela ocasião. $\mathrm{O}$ menino relatou, então, que nem todos os monitores os espancavam e que os mais velhos é que eram mais legais, que trocavam ideia com eles. Fiquei surpresa, pois, em geral, são justamente os mais velhos que não têm uma formação específica em relação à ideia de socioeducação. Outra coisa surpreendente que ele falou é que ele achava que deveriam colocar câmeras internas em toda a instituição: "assim ia dá pra ver se a gente fez pra merecer ou não". Eu disse que assim eles seriam vigiados o tempo todo e ele disse que não fazia mal: o ruim era apanhar injustamente. Entre os castigos arbitrários e a vigilância, ele preferia esta última. O "ser visto" a todo tempo parece melhor do que o "ser pego e castigado" a qualquer tempo.

Tais trechos das narrativas podem ser "lidos" de diversas maneiras. Constituem por eles próprios a denúncia de um sistema que se pretende socioeducativo. Essas narrativas falam da prevalência de práticas punitivas pautadas pelo suplício, pelo castigo e pela tortura em tempos de regime democrático e aplicadas justamente ao público ao qual foi preconizada uma condição diferenciada no que tange ao sistema penal.

Os relatos apresentados convergem com as descrições presentes em relatórios do Conselho Nacional de Justiça, bem como com outros documentos acerca de execuções sumárias de adolescentes em confrontos com a polícia no estado de Santa Catarina. É sem dúvida notável haver situações como essa em Florianópolis, capital que ocupa a quarta posição no Índice de Desenvolvimento Humano (IDH) dos municípios brasileiros. Porém, o paradoxo se desfaz quando lembramos que boa parte da população demanda "direitos humanos para humanos direitos" e, de certa forma, legitima reprodução das situações acima descritas. Mas 
é preciso ir além da denúncia, do mal-estar e da tristeza que sentimos ao ler cada relato e procurar compreender o que tais situações produzem, além de abuso e de vitimização.

Uma leitura mais analítica dessas situações poderia estar na elucidação de como a tortura, as violências em relação ao corpo e à mente são significadas por esses sujeitos e como atuam em suas constituições subjetivas. Acerca desse aspecto, remeto ao trabalho de David Le Breton (2010) no qual ele analisa, dentre outras "experiências da dor", a tortura como "fratura de si". Nas suas reflexões sobre pessoas que sofreram torturas - no contexto de situações de guerra e de governos ditatoriais -, predomina a ideia de "implosão do sentimento de identidade", de "fratura da personalidade". Não creio ser esse o caso nas experiências dos adolescentes contatados. Eles relatavam as situações de tortura e dos castigos recebidos sem bloqueios. As marcas, as cicatrizes entre eles não são escondidas, não são motivo de vergonha - ao menos em nossa interação e entre eles -, mas são apresentadas como um sinal de força, de sobrevivência, de caráter/ética, como no caso de resistir e não delatar os companheiros. Como aprendi com eles, na constituição de seus corpos e mentes o "veneno fortalece". A passagem por essas situações compõe a "vida no crime", é uma de suas faces de sofrimento, mas é encarada como uma parte mais ou menos esperada, assim como "hospital, cadeia, caixão".

Contudo, há uma característica apontada por Le Breton (2010) e que atinge de maneira muito forte os adolescentes: a quebra da confiança em relação ao mundo ordinário por conta da introdução do imprevisível nessas experiências. Acredito, contudo, que em nosso caso isso se dá não apenas por conta das situações de tortura, mas de uma série de situações de imprevisibilidade: a qualquer momento pode haver um conflito com a polícia, com grupos rivais, com desafetos; em uma hora tem-se tudo - dinheiro, mulheres, amigos - e logo em seguida pode-se perder tudo.

Essa questão da normalidade, da não interpretação das situações em termos de "trauma" e de sua ressignificação em termos de "fortalecimento" nos leva a pensar sobre quais são os intoleráveis, os abusos para esses jovens; o que para eles extrapola, o que para eles é violência. Vale lembrar aqui a fala do menino que preferia câmeras à arbitrariedade dos castigos: ele não colocou em questão os castigos em si, mas o fato de serem gratuitos, "sem a gente merecer". O abuso, para esse adolescente, não era o uso da força física, mas sua arbitrariedade. Por outro lado, uma das meninas afirma que bater, surrar adolescentes é ilegal. Ela questiona e critica não apenas a arbitrariedade, mas os castigos, a violência física por eles próprios. Entretanto, como apontado, ela faz uma operação de ressignificação, de agenciamento diante de uma situação de castigo: "Mas eu gostava de ficar no quarto, que eu não tinha que olhar pra cara delas [...]".

No caso dos meninos e meninas que passam por diversas situações de violência nesse contexto, dos que vivem um profundo "envolvimento com o crime" e que afirmam ter consciência das consequências, inclusive uma possível morte violenta - "caixão" -, tenho a impressão de que vão constituindo um corpo e uma "mente" resistentes a toda forma de violência dirigida a eles próprios. Para a maioria desses, a "vida longa, segura" não é um valor central e a dignidade de uma pessoa parece concentrar-se no "respeito" e na "consideração" que ela atribui a outrem e que a ela são atribuídos. O sacro, o intocável podem ser, por exemplo, figuras como as mães, as avós e mesmo os objetos que remetem a elas. Vale mais morrer como "sujeito homem" do que viver o resto dos dias como delator, "traíra", "verme". Um tapa na "cara" pode ser pior do que um espancamento. Na "X 
Reunião de Antropologia do Mercosul", debatemos o trabalho de Claudia Briones e de Marcela Tomás (2013) sobre Sentidos y territorios vivenciales de violencias $y$ violentamientos en situaciones de encierro. Ali também chamou muito a atenção o fato de que, em relação às violações descritas pelas autoras, o que internos consideravam abuso se relacionava à ideia de desrespeito, especialmente no que toca a situações que repercutiam de alguma forma em pessoas pelas quais eles tinham afeto.

É importante lembrar que a consciência da possibilidade de morte violenta seja em confrontos, seja por "pisadas" - e o foco na intensidade das experiências e não em sua extensão não devem ser tomados como desleixo com a vida. Há uma vontade de vida nessas vidas que se sabem breves. Essa vontade se manifesta nos agenciamentos, nas contra-sujeições que estão presentes em momentos tão limítrofes. Uma das maneiras encontradas pelos adolescentes para resistir e para fazer algo diante das violações no interior das instituições é a rebelião. Alinho-me aos argumentos de Maria Cristina Vicentin (2005), que perspectiva as rebeliões como "acontecimentos-resistência", como "linhas de fuga" ante os aparatos de repressão, vigilância e extermínio.

Durante um dos dias da pesquisa de campo na Casa, chegaram alguns adolescentes "novos" após uma rebelião em um centro de internação. Eles me perguntaram se eu sabia do acontecido: "Quebramo tudo". Relataram que estavam apanhando frequentemente dos monitores. De acordo com os jovens, eles entravam nas celas, batiam, davam chutes e choques. O diretor da instituição teria mesmo demonstrado pena em certa ocasião diante do estado em que estava um dos internos, contudo fez "vista grossa". Segundo os adolescentes, a gota d'água foi um tapa no rosto de um dos internos. Aí vale lembrar o que discuti acima sobre o limite do tolerável, que, nesse caso, parece ser mais moral do que físico. Contaram, ainda, que, no dia em que se rebelaram, foram destruindo tudo com chutes e que, com as pedras de concreto das coisas quebradas, acertavam o resto. A Polícia Militar foi chamada. Antes de ser algemado, um deles ainda bateu em um dos monitores. Foram para o pátio com as mãos para cima e deviam também tirar a roupa, ficando apenas com a roupa de baixo. Quem estava sem cueca ficou sem nada mesmo. Ainda, segundo o relato, ficaram de joelhos em frente aos policiais e começaram a cantar uma música cuja letra dizia: "Matar os polícia é a nossa meta" (Apologia, Mc Daleste). Perguntei se eles não tinham medo e eles disseram que não: "os caras" não podiam matar eles ali; e, se matassem, "fazer o quê? Essa vida é isso mesmo. O cara sabe que vai morrer". Resistir, mesmo ou principalmente diante da possibilidade da morte, é uma maneira de tornar-se sujeito, de não ser apagado, subsumido, violado.

Em síntese, nesse processo, esses adolescentes constituem corpos resistentes em que o "veneno" e "o sofrimento" fortalecem, bem como um caminho que seguem a despeito de o ponto de chegada ser "hospital, cadeia, caixão". No entanto, eles também falaram sobre outras dimensões "dessa vida" que envolvem emoções e sensações bem diversas daquelas relacionadas ao "veneno", como, por exemplo, a diversão, a adrenalina, a aventura.

\section{Emoções e alterações: a "adrenalina", o uso de "drogas", a medicalização}

Quando narravam suas histórias havia um momento do relato, quase sempre o primeiro, no qual a entrada na vida no crime era dotada de sentido, era justifi- 
cada. Se há aí uma espécie de "neutralização moral”, é porque se trata de um discurso que é fruto de uma interpelação; um discurso "para fora" em que há a necessidade de criar uma comunicação entre mundos que são colocados como coisas distintas. Em um segundo momento, seguindo esse esforço de se comunicar, o relato passava a descrever elementos de transição, de passagem entre mundos: o "enturmamento", os conflitos e rupturas com as instâncias que representam o que se está "deixando" - família e escola. Seguia uma terceira etapa na qual já se estava no "mundão". As descrições ganhavam vivacidade; o tom mais sério e, por vezes, triste dava lugar a falas e a gestos cheios de emoção. Eram, então, descritas as aventuras "no crime": os assaltos, as fugas da polícia. Mas a emoção e a intensidade nem sempre tinham esse caráter de adrenalina; era o mesmo momento em que falavam sobre o "veneno".

Voltemos à questão das emoções relativas à intensidade. Para grande parte dos adolescentes com que se teve contato, o aspecto da experienciação da adrenalina como motivador e como um fator que reforça os pontos positivos da "vida no crime" não pode ser negligenciado. Vale lembrar que para alguns a adrenalina não define e nem explica a experiência "no crime" - "é coisa de playboy que se envolve por fama e por prazer" - enquanto para outros é citada como algo fundamental. Assim como marcadores de gênero - tais como o "ethos guerreiro" - não dão conta de toda a experiência no crime, o jogo com as emoções e com os limites pode ser pensado como um elemento, dentre outros, importante na configuração da "vida no crime" e dos modos de subjetivação que se constituem a partir dela.

A ideia da aventura, do movimento, da adrenalina permeava as concepções e as experiências cotidianas dos jovens contatados. A experimentação com os limites não apareceu somente nas descrições sobre as atividades ligadas ao "crime", mas também em outras situações presenciada, como o fato de eles entrarem no mar ou em uma lagoa durante o inverno, com a água fria. Rubens educador da Casa que quando adolescente cumpriu medidas - contou uma série de "aventuras" que viveu em sua infância e adolescência. Ele e seus amigos inventavam várias brincadeiras que envolviam suspense, superação de medos e desafio da linha entre a morte e a vida. Todas essas experiências eram uma forma de diversão, mas também podemos entendê-las, seguindo Le Breton (2004; 2007), como rituais de passagem, de busca de sentido e de "gosto pela vida", bem como de desafio aos limites para justamente se inscrever na vida, constituir-se.

Mas, na vida dos adolescentes em questão, a sensação de adrenalina, em muitas situações, estava associada à prática de infrações, especialmente nos casos de assaltos. Para Maria Eduarda, audaciosa e focada no presente, a dimensão positiva dessa emoção era tão forte que a fazia nada temer. Quando perguntada se não tinha medo de morrer, disse: "Não. Nem pensava nisso na real. Nem pensava no que ia acontecer, só pensava em coisa boa, mesmo, curtindo ali, com os amigos, né"?

A adrenalina parece ser um tipo de emoção que, dependendo da pessoa ou do contexto, envolve sentimentos distintos como prazer e medo. Além disso, exige ou promove uma determinada postura, como explicou Luiz Paulo: "Um nervoso com atitude, né? Que também o cara quer mostrar pros amigo do cara também que o cara não é coisa, né? Quer mostrar que o cara é...”.

Nas experiências de infração, a sensação de adrenalina estava associada a situações de perigo, de risco de morte, bem como de enfrentamento e, por sua vez, de demonstração de coragem, de perspicácia. Havia também situações que não envolvem adrenalina no momento da infração, mas que visavam à diversão, como 
no caso narrado por Jéferson, que roubava motos para se divertir, para aprender a andar, para ir a festas.

Uma das pistas para pensar a relação entre a adrenalina e o cometimento de infrações pode ser encontrada em Jack Katz (1988) que é uma referência um tanto quanto desconcertante - e, por isso mesmo, fundamental - em sua análise fenomenológica dos "atrativos morais" e "sensórios" do crime. Seu foco está na coerência situacional das práticas. Além disso, nas obras de David Le Breton, especialmente sobre as "condutas de risco" entre adolescentes, tais práticas - nas quais o traço comum consiste na exposição de si a uma probabilidade não negligenciável de morrer ou de se ferir - são interpretadas como ritos ordálicos ou como ritos de passagem contemporâneos nos quais o jovem "joga" com a morte buscando significado para sua existência. No caso da "delinquência juvenil" o autor também sinaliza o aspecto do prazer da transgressão. A delinquência e a violência, nesse contexto, inserem-se na busca de sensações, como uma maneira intensa de entrar em contato com o mundo (LE BRETON, 2004; 2007).

Existem sempre nuances. Felipe, ao responder sobre se sentia adrenalina, alguma sensação boa, expressa uma espécie de amortecimento das emoções ao longo de suas experiências no crime: "Normal, eu ajo normal, como se não fosse nada".

\section{Uso de substâncias psicoativas}

A grande maioria dos interlocutores nas duas experiências de pesquisa não apenas trabalhava no comércio de drogas, mas também fazia uso de algum tipo de droga lícita ou ilícita. Havia graus de "envolvimento" diversos em relação ao uso bem como diferentes maneiras de se "relacionar" com as substâncias. Mas, mostrou-se recorrente o fato de o sistema socioeducativo desconsiderar que muitos desses jovens eram, além de "traficantes", dependentes químicos e, desse modo, não prever e garantir tratamentos adequados. Outro elemento que se repetiu se refere a uma dimensão mais "nativa" da questão no sentido de que havia uma série de interdições e prescrições e a figura do usuário de crack ("casqueiro") como símbolo do interdito, do sujo, do excesso, do anormal.

Boa parte dos adolescentes relatou que fazia uso de maconha. Para eles, se houvesse uma escala, a maconha estaria quase fora da categoria drogas: "nunca usei nada, só maconha". O uso era legitimado, permitido e recorrente no grupo, e foram ressaltadas por eles as sensações de relaxamento, de calma. Alguns jovens contaram que faziam uso também de tabaco. Vários meninos disseram que em festas bebiam e, por vezes, usavam cocaína e/ou "balas", “doces" (ecstasy, LSD). Como contou Luiz Paulo, em alguns lugares há interdições claras quanto ao uso de drogas - com a exceção da maconha - pelos "trabalhadores do tráfico", de forma que os negócios não sejam prejudicados.

Nos discursos em relação à interdição ao crack, aparecia essa questão da possibilidade de prejuízos financeiros, mas, estavam presentes também avaliações, julgamentos morais. O "casqueiro" não é confiável para trabalhar no tráfico e, além disso, ele é um sujeito que não é capaz de "correr pelo certo", de seguir as normas compartilhadas. Ele é ainda, uma das posições de sujeito com uma vida "matável” dentro das avaliações que são feitas no grupo em relação a quem pode/deve ser punido com a vida em caso de dívidas, de "pisadas".

Para alguns deles o uso de algumas substâncias, especialmente a cocaína, estava atrelado ao cometimento de infrações, funcionando como um aditivo de emoção e adrenalina e/ou como um encorajador: 
Oh, parecia que, meu Deus, oh... parecia que o mundo... Se me desse uma arma e um policial na frente, a gente se matava, eu e o policial. Porque é um poder, sabe? Eu acho que pior que presidente da república, assim, tu se sente muito, demais.... É ruim, sabe? É ruim. (Fernanda)

\author{
E pra roubar sempre cheirava? \\ É, sempre cheirava. \\ E aumentava a adrenalina? \\ Aumentava. Ô ô, aumentava mesmo. \\ E como é que era, assim? \\ Ah, tipo uma, não sei, uma sensação, eu não sei, não tem como explicar. É tipo, por \\ exemplo... tu bota um negócio na mente, daí a adrenalina já vai, já te impulsa, já faz \\ as coisas no impulso, já. Daí faz. Não tá nem aí pra ninguém... (Jonas)
}

A cocaína atuava, assim, como mais um dos componentes de uma vida que se constitui na intensidade. A interação entre drogas, sujeitos e crime promove, de acordo com os contextos e com as substâncias, "alter-ações" de encorajamento e incremento das fortes emoções, de relaxamento e de tranquilidade, entre outras. Nesse sentido, é pertinente a contribuição de Eduardo Viana Vargas (2006) sobre o tema quando sugere que não é suficiente indagar "por que as pessoas usam drogas?”, mas “o que ocorre em práticas como essas?”, "que experiência usuários e substâncias realizam?" As respostas que surgem para esse outro conjunto de questões apontam para a existência de eventos - as "ondas" das drogas - que, de acordo com Viana, envolvem agenciamentos paradoxais de autoabandono e modos singulares de engajamento no mundo, nos quais as substâncias são mediadores indispensáveis.

Essa abertura para o reconhecimento de modos plurais de viver a vida nos quais a vida intensa mobiliza uma determinada série de drogas é um movimento importante também na análise da "vida loka". Isso não quer dizer que se desconsidere o uso de drogas ilícitas entre crianças e adolescentes como um problema sério a ser enfrentado por toda a sociedade. Vale lembrar aqui outro problema grave e pouco encarado como "problema": a indicação e o uso abusivo, indiscriminado, aleatório de drogas lícitas como a ritalina - considerada a droga da "disciplina" - para crianças e jovens em vários lugares do mundo, inclusive nas instituições de semiliberdade visitadas.

Um último ponto importante é a questão do tratamento, ou melhor, da falta dele. Diante da inexistência de instâncias formais, da restrição ao acesso a profissionais especializados, sobressaiu o agenciamento dos próprios adolescentes. Vários relataram que, sozinhos, deixaram de usar uma ou outra droga. É claro que são casos pontuais, que muitos deles voltam a fazer uso das substâncias que deixaram de usar, mas é preciso considerar essa questão colocada por eles em termos de "botar na mente", "ter a cabeça forte". Júlia, por exemplo, conseguiu deixar de usar crack quando foi internada na semiliberdade. Novamente é possível identificar movimentos de agenciamento por parte desses jovens, seja no jogo com a vida intensa, seja na busca pelo autocontrole.

\title{
Medicalização
}

Nas experiências de campo, especialmente na Casa de Semiliberdade, chamou a atenção a medicalização intensiva dos adolescentes. Em um mural na sala dos educadores ficava uma lista de jovens que tomavam medicação contínua como ritalina, antidepressivos, estabilizantes do humor. Não se trata aqui de culpabilizar a instituição pela maneira como conduzia a questão. A Casa reproduzia e aderia a uma configuração contemporânea das biopolíticas, públicas ou não, nas quais acesso à saúde é sinônimo de acesso a medicamentos (FASSIN, 2010; 
MALUF, 2012). A ritalina, por exemplo, vem sido receitada indiscriminadamente para crianças e adolescentes das diversas classes sociais. No caso de alguns adolescentes, acumulam-se em seus corpos efeitos das drogas ilícitas e lícitas. A vida na instituição e a determinação de alguns os tinha feito deixar de usar cocaína e crack, como discutiu-se anteriormente, mas os tinha aproximado de drogas fortíssimas que nossa sociedade propaga, legitima e dissemina posto que contam coma assinatura de uma parte significativa da ciência e da medicina. É curioso também que alguns estavam ali privados de liberdade por conta de "tráfico de drogas": o mesmo Estado que pune a venda de algumas drogas, prioriza e incentiva em suas políticas o uso de outras drogas. Fernanda Bittencourt Ribeiro (2013) em seu trabalho sobre a "lei da palmada" chama a atenção para a seguinte incongruência: de um lado a ampliação da noção de violência para toda prática que provoque dor e de outro a disseminação de drogas "de obediência" que anestesiam as crianças.

\section{O lugar das emoções "na vida do crime"}

Há uma série de dimensões que compõem a experiência no crime. Em cada uma, há valores, linhas de sujeição e/ou subjetivação, mundos de referência. Todas atravessam os jovens em questão e cada uma delas é acionada de acordo com os contextos de ação e de comunicação e de acordo com os sujeitos em relação (VIEIRA, 2014).

Como se mencionou, a questão "por que entrou no crime" interpela os sujeitos a darem sentido, explicações sobre sua conduta como desvio. É uma instância em que estão pressupostos um domínio da ordem e outro das rupturas em relação à ordem. Nela entram em cena os processos de produção da delinquência, de nominação, de seletividade e as categorias que enquadram os sujeitos como delinquentes, infratores, criminosos, em conflito com a lei.

Outra dimensão, um dos focos do presente artigo se refere a estar no crime apesar disso significar "hospital, cadeia e caixão". Aqui é possível pensar que se abre um espaço de resistência, de afirmação de um sujeito que - embora institucionalizado ("vida nua", sujeita à tortura, à matabilidade), sofredor - elabora o veneno que corre em suas veias, as cicatrizes que marcam seu corpo e as modulações que pressionam sua alma, em termos de fortalecimento. A consciência de que se pode ser torturado, humilhado, espancado, "preso" e morto e, apesar disso, e partir disso, seguir nesse caminho. Judith Butler (2006) coloca que as bases para uma comunidade estão relacionadas à nossa exposição e à nossa cumplicidade com a violência, com a nossa vulnerabilidade à perda e ao trabalho de luto que a segue. Para ela, em parte, cada um de nós se constitui politicamente em função da vulnerabilidade social de nossos corpos - como lugar de desejo, de vulnerabilidade física, de afirmação e de exposição. O surpreendente, no caso desses jovens, é que suas vidas, aos olhos de fora "abjetas", "matáveis", são constituídas por eles como vidas que valem a pena ser vividas, apesar disso. E essas vidas para eles têm sentido, são afirmadas na maneira como são vividas. É aí que entra a terceira dimensão: como se vive nessa vida.

Ela é digna de ser vivida por sua intensividade - "viver pouco como um rei" -, pelas sensações (adrenalina, aventura, diversão) que ela proporciona e porque nela corre-se pelo certo. Nela forma-se uma comunidade de valores, uma comunidade política na qual devem prevalecer o respeito e a humildade entre os membros, de modo que todos se sintam devidamente "considerados". Há aí, ao menos 
como horizonte e como objeto de problematização moral, a constituição de um sujeito ético, o "sujeito-homem".

Diferentes emoções como o "veneno" e a adrenalina fazem parte, assim, de um quadro mais geral das dimensões de uma determinada experiência, de um certo estar no mundo. Elas constituem determinados corpos e participam centralmente dos processos de subjetivação desses adolescentes na "vida do crime". Além disso, possibilitam o questionamento de categorias e compreensões ortodoxas de corpo, de vida e de sujeito, apontando para a multiplicidade de lógicas de produção de si.

Recebido 31 de agosto de 2019.

Aprovado 28 de janeiro de 2020.

\section{Referências}

BRIONES, Claudia; TOMÁS, Marcela. Sentidos y territorios vivenciales de violencias y violentamientos en situaciones de encierro. Apresentação trabalho $X$ $R A M$. GT 64: Muertes, violencias y territorio: sentidos y escenarios en América Latina. CD-ROM, Córdoba, 2013.

BRUNER, Edward M. "Ethnography as Narrative". In: TURNER, Victor W.; BRUNER, Edward M. The Anthropology of Experience. University of Illinois Press. Urbana and Chicago, 1986.

BUTLER, Judith. Vida precaria: el poder del dueloy la violencia. Front Cover.Editorial Paidós, 2006.

FASSIN,Didier. La raison humanitaire: une historie morale du temps présent. Paris: Seuil/Gallimard, 2010.

FEFFERMANN, Marisa. Vidas arriscadas. O cotidiano dos jovens trabalhadores do tráfico. Petrópolis: Editora Vozes, 2006.

KATZ, Jack. Seductions of crime. Moral and sensual attractions in doing evil. New York: Basic Books, 1988.

LANGDON, Esther Jean. "DAU”. In: Religião, Magia ou Feitiçaria. O Pensamento Antropológico sobre o Xamanismo. Trabalho apresentado para o Concurso de Professor Adjunto na Universidade Federal de Santa Catarina (cópia de versão impressa), 1988.

LE BRETON, David. Les conduites à risque des jeunes: des violences sur soi à celles sur les autres. Bulletin de L'Académie Nationale de Médecine, 188 (8): 1313-1322, 2004.

LE BRETON, David. En souffrance. Adolescence et entreé dans la vie. Paris: Éditions Métailié, 2007. 
LE BRETON, David. As paixões ordinárias: antropologia das emoções. Petrópolis: Vozes, 2009

LE BRETON, David. Expériences de la douleur: entre destruction et renaissance. Paris: Éditions Métailié, 2010.

MALUF, Sônia W. Antropologia, Narrativas e a busca de sentido. Horizontes Antropológicos, 5 (12): 13-37, 1999.

MALUF, Sônia W. Réflexion sur les expériences sociales et les politiques publiques dans le domaine de la santé mentale au Brésil. Antropologia em primeira mão, 133, 2012.

NIETZSCHE, Friedrich. Genealogia da Moral: uma polêmica. São Paulo: Companhia das Letras, 1998.

OCHS, Elinor. "Narrativa". In: El discurso como estrutura y proceso. Estudios del discurso: introduction multidisciplinaria. Barcelona: Gedisa, 2000.

RIBEIRO, Fernanda Bittencourt. Governo dos adultos, governo das crianças: Atores, práticas e discursos a partir da lei da palmada. (Dossiê Infâncias e Crianças: saberes, tecnologias e práticas). Civitas - Revista de Ciências Sociais, 13 (2): 292-308, 2013.

RIFIOTIS, Theophilos. Alice do outro lado do espelho: revisitando as matrizes das violências e dos conflitos sociais. Revista de Ciências Sociais, 37 (2): 27-33, 2006.

ROSALDO, Renato. "Narrative Analysis". In: Culture and Truth: The Remaking of Social Analysis. Boston: Beacon Press, 1993.

VARGAS, Eduardo Viana. Uso de drogas: a alter-ação como evento. Revista de Antropologia, 49 (2): 581-623, 2006.

VICENTIN, Maria Cristina G. A vida em rebelião: jovens em conflito com a lei. São Paulo: Hucitec/Fapesp, 2005.

VIEIRA, Danielli. Vivendo "no veneno": Análise de narrativas contadas por jovens sobre homicídios em Santa Catarina. Dissertação (Mestrado em Antropologia Social). Centro de Filosofia e Ciências Humanas, Universidade Federal de Santa Catarina, 2009.

VIEIRA, Danielli. "Vivendo no veneno": narrativas contadas por jovens sobre homicídios em Santa Catarina. In: RIFIOTIS, Theophilos; VIEIRA, Danielli (orgs.). Um olhar antropológico sobre violência e justiça: etnografias, ensaios e estudos de narrativas. Florianópolis: Ed. da UFSC, 2012.

VIEIRA, Danielli. Correndo pelo certo, vivendo no crime: moral, subjetivação e comensurabilidade na experiência de adolescentes em cumprimento de medidas socioeducativas. Tese (Doutorado em Antropologia Social). Centro de Filosofia e Ciências Humanas, Universidade Federal de Santa Catarina, 2014.

ZALUAR, Alba. Condomínio do Diabo: as classes populares urbanas e a lógica do ferro e do fumo. Rio de Janeiro: Editora da UFRJ, 1995. 